\title{
Exosomes Derived from SW480-Resistant Colon Cancer Cells are Promote Angiogenesis via BMP- 2/Smad5 Signaling Pathway
}

\section{Song Yang}

lu'an hospital of anhui medical university

\section{Lei Yao}

lu'an hospital of anhui medical university

\section{Xiaolong Wang}

lu'an hospital of anhui medical university

Hao Sun

lu'an hospital of anhui medical university

\section{Chaogang Du}

lu'an hospital of anhui medical university

\section{Chengpeng Song}

lu'an hospital of anhui medical university

Jingyu Fu

lu'an hospital of anhui medical university

\section{Yongjun Wu}

lu'an hospital of anhui medical university

\section{Hongwu Huang}

lu'an hospital of anhui medical university

\section{Chuansi Wang}

lu'an hospital of anhui medical university

\section{Yongsen Wang}

lu'an hospital of anhui medical university

Yixiang Xie ( $\nabla$ Xieyixiang1968@163.com )

lu'an hospital of anhui medical university

\section{Research Article}

Keywords: Colon cancer, Exosomes, BMP-2, Angiogenesis

Posted Date: July 12th, 2021

DOl: https://doi.org/10.21203/rs.3.rs-695878/v1 
License: (c) (i) This work is licensed under a Creative Commons Attribution 4.0 International License. Read Full License 


\section{Abstract}

Background: Multidrug resistance is the main cause of tumor recurrence and metastasis. Therefore, it is urgent to explore the mechanism and treatment of drug resistance of tumor cells. We aim to investigate the relationship between drug resistance and angiogenesis in SW480 colon cancer cells, and the possible underlying mechanism.

Methods: Exosomes was extracted from SW480-sensitive or -resistant colon cancer cells (SW480/Oxaliplatin). MTT assay, migration assay, tube formation assay, qPCR and Western blotting were performed in human umbilical vein endothelial cells (HUVECs).

Results: The conditioned medium and exosomes of SW480/Oxaliplatin cells promoted proliferation, migration, and tube formation of HUVECs. The expression of BMP-2 in SW480/Oxaliplatin exosomes was 2.3 folds higher than that in SW480 exosomes. BMP-2 promoted angiogenesis in vitro by inhibiting the Smad signaling pathway. Moreover, TGF- $\beta 1$, an activator of the Smad signaling pathway, could partly block the promoting effect of SW480/Oxaliplatin exosomes on angiogenesis.

Conclusions: SW480 resistant colon cancer exosomes promoted angiogenesis via inhibiting the BMP2/Smad signaling pathway.

\section{Introduction}

Colorectal cancer (CRC) is one of the most common gastrointestinal malignancies, with the third highest incidence and the second highest mortality in all malignant tumors [1, 2]. Chemotherapy is the primary treatment for advanced metastatic tumors [3]. However, multidrug resistance (MDR) often leads to poor efficacy of chemotherapy $[3,4]$. The proliferation of drug-resistant cells is accelerated and metastases to distant regions, promoting increased angiogenesis [5]. Clinically, it is often found that tumor cells have multi-drug resistance to a variety of chemotherapy drugs, resulting in tumor recurrence and tumor metastasis. Therefore, it is of great significance to explore the mechanism and treatment of tumorresistant cells.

Exosomes are nanoscale vesicles with a diameter of 30-100nm secreted by a variety of living cells, which can be stable in body fluids and play the role of information transmission between cells [6]. Exosomes contain a large number of maternal-cell-derived substances, including proteins, nucleic acids and lipids, which participate in the regulation of tumor microenvironment in the way of transmitting material information [6]. It involved in tumor growth, invasion and metastasis, immune escape, chemotherapy resistance and radiotherapy tolerance $[7,8]$. Studies on pancreatic ductal adenocarcinoma, breast cancer, ovarian cancer, liver cancer and lung cancer have all shown that exosome transport is involved in chemotherapy resistance [9-11]. Exosomes secreted by tumor cells and stromal cells enhanced and induced drug resistance in recipient cells by transferring their contents (DNA, mRNA, miRNA, Lnc RNA, protein, etc.) into recipient cells to alter their phenotype. However, few studies have focused on the effect of exosomes on tumor angiogenesis, especially in colon cancer. 
Bone morphogenetic protein 2 (BMP-2) is a highly closed live opalics contained in the family of transgenic growth factor- $\beta$ (TGF- $\beta$ ) [12]. The main biological function of BMP-2 is to regulate cell proliferation, chemotaxis and apoptosis, which is closely related to the growth and development of embryos, aging and canceration [12]. Studies have shown that BMP2 is involved in the process of apoptosis, migration and invasion of CRC, liver cancer, gastric cancer and lung cancer [13-15], and affects the release of immune factors by tumor cells. Feng et al. found that BMP2 was highly expressed in liver cancer tissues [16]. Overexpression of BMP2 promoted cell proliferation, migration, invasion, microvascular density and angiogenesis, and reduce cell apoptosis [16]. However, the role of BMP-2 in drug resistance and angiogenesis is not fully understood.

In this study, we investigated the relationship between drug resistance and angiogenesis in human colon cancer SW480 cells. In addition, we also determined the role of SW480 cancer cell exosomes in angiogenesis and its potential mechanism.

\section{Materials And Methods 2.1 Cell culture}

SW480 colon cancer cells and SW480/Oxaliplatin cells were cultured in L-15 medium containing 10\% fetal bovine serum and $1 \%$ penicillin/streptomycin. Conditioned medium (CM) was collected after cells were cultured in exosome-free FBS medium for $48 \mathrm{~h}$. Human umbilical vein endothelial cells (HUVECs) were purchased from the cell bank of Chinese Academy of Sciences (Shanghai, China) and were cultured in RPMI 1640 medium containing 10\% fetal bovine serum. All cells were were inoculated in T25 flask and cultured in an incubator at $37^{\circ} \mathrm{C}$ with $5 \% \mathrm{CO}$. The subculture was performed once every 2 to 3 days.

\subsection{Exosomes isolation}

The $\mathrm{CM}$ was prepared for the exosomes isolation. All of the following centrifugations occurred at $4{ }^{\circ} \mathrm{C}$. $\mathrm{CM}$ was centrifuged at $300 \times \mathrm{g}$ for $10 \mathrm{~min} ; 2000 \times \mathrm{g}$ for $10 \mathrm{~min} ; 10000 \times \mathrm{g}$ for $30 \mathrm{~min}$; and then at 140,000 $\times \mathrm{g}$ for $90 \mathrm{~min}$. After the supernatant is removed, the precipitate obtained is called exosome. The precipitation was washed and resuspended with PBS buffer, and then was centrifuged again at 140 $000 \times \mathrm{g}$ for $90 \mathrm{~min}$. Finally, the precipitates were resuspended with $100 \mu \mathrm{L}$ PBS buffer and frozen at $-80^{\circ} \mathrm{C}$. The morphology of exosomes was detected by transmission electron microscopy (TEM, Hitachi, Japan). 2.3 Cell viability assay

The cells were collected by centrifugation and made into cell suspension at a concentration of 5$10 \times 104 / \mathrm{mL}$. 100ul cell suspension was seeded into 96 -well plates. The inoculated cell culture plates were placed in the incubator for $2 \mathrm{~h}$. The culture supernatant was removed from the 96 -well plate and 100ul of medium containing different concentrations of drugs was added. After incubation for 12, 24, 48 $\mathrm{h}, 10 \mathrm{ULMTT}$ solution $(5 \mathrm{mg} / \mathrm{mL})$ was added to each well and continued for $4 \mathrm{~h}$. The 96 -well plate was gently inverted to remove the supernatant. 150ul dimethyl sulfoxide was added to each well and shaken at low speed for $10 \mathrm{~min}$ to make the crystals fully dissolved. Finally, the value of optical density was measured at $490 \mathrm{~nm}$. 


\subsection{Cell migration assay}

Transwell Boyden Chamber was used for cell migration assay. The gel was reconstructed by adding 200 microl DMEM medium to each well. 10\%FBS medium $600 \mu \mathrm{l} /$ well was added in Transwell lower chamber. Cells were added into Transwell upper chamber and cultured for $24 \mathrm{~h}$. After discarding the upper chamber fluid, cells were fixed with $10 \%$ neutral formaldehyde for $10 \mathrm{~min}$ and then stained with Giemsa for $10 \mathrm{~min}$. After three times of PBA washing, three fields were randomly selected under an inverted microscope to count the number of cells.

2.5 Tube formation assay

HUVECs were planted in a six-well plate and grew to $100 \%$ fusion density. Matrigel solution was diluted to $0.05 \%$ in the medium $(0.5 \mathrm{mg} / \mathrm{mL})$. The cells were grown in medium with $0.05 \%$ Matrigel for $24 \mathrm{~h}$. A similar tubular structure was observed under a microscope $(\times 10)$.

\subsection{Immunofluorescence}

The prepared cell slides were soaked and washed with PBS for 3 times ( 5 min per time). The slides were fixed with $4 \%$ paraformaldehyde for $15 \mathrm{~min}$, and then soaked with PBS for 3 times. Then cells were permeabled by $0.5 \%$ Triton X-100 at room temperature for $20 \mathrm{~min}$. After washing with PBS, cells were blocked with $5 \%$ goat serum for $30 \mathrm{~min}$ at room temperature. After washing off the blocking fluid, cells were incubated overnight with the primary antibody TGFBR3 at $4^{\circ} \mathrm{C}$. The slides were soaked and washed with PBST for three times and incubated with fluorescent secondary antibody at $20-37^{\circ} \mathrm{C}$ for $1 \mathrm{~h}$. After the nucleus is stained with DAPI, images were captured using confocal microscopy.

2.7 RNA extraction and quantitative reverse transcriptase-PCR (qRT-PCR)

Total RNAs were extracted from cells with TRIzol Reagent (Thermo Fisher Scientific). After quantitation, RNA was reverse to cDNA using a PrimeScript RT reagent kit (Takara, Shiga, Japan), and then quantitative real-time PCR was performed by using SYBR Premix ExTaqTM II (Takara). The mRNA levels were normalized to GAPDH and the primers used above were listed in the Supplementary Table 1.

2.8 Western blotting assay

The total proteins were extracted from cells or exosomes and quantified by the BCA assay kit (Beyotime Biotechnology, Shanghai, China). Proteins were separated on a $10 \%$ SDS-PAGE gel on ice and then transferred onto a PVDF membrane. After blocking with $5 \%$ bovine serum albumin (BSA), PVDF membranes were incubated with primary antibodies (VEGF, CD31, CD9, CD63, CD81, TGFBR3, Smad5, phosphorylated Smad5) overnight at $4^{\circ} \mathrm{C}$ and then goat anti rabbit $\operatorname{lgG}$ at room temperature for $1 \mathrm{~h}$. Bands were visualized by an ECL system. All antibodies used above were purchased from Cell Signaling Technology and Proteintech.

2.9 Statistical analysis

Data were expressed as mean \pm SD and analyzed for the significant difference using SPSS 22.0. The differences between two groups were analyzed by student's t-test, and multiple groups were by one-way ANOVA. $P$ less than 0.05 was considered statistically significant.

\section{Results}

\subsection{Conditioned medium (CM) extracted from SW480- resistant colon cancer cells enhance angiogenesis.}


We explored the mechanisms of tumor angiogenesis by using SW480 and resistant colon cancer SW480/Oxaliplatin cells. After culturing, the CM of both cells were collected and co-cultured with HUVECs. Compared with the CM of SW480 cells, the CM of SW480/Oxaliplatin cells promoted cell activity of HUVECs (Fig. 1A). Figure 1B and 1C found that the number of migration and tube formation of HUVECs in the SW480/Oxaliplatin group was 1.64 and 1.28 times higher than that in the SW480 group. Additionally, the CM of SW480/Oxaliplatin cells increased the mRAN levels and protein expression of VEGF and CD31 (markers of endothelial cell function) of HUVECs (Fig. 1D and E). These findings suggested that the CM of SW480/Oxaliplatin cells promoted the proliferation, migration, and tube formation of HUVECs.

\subsection{Exosomes extracted SW480/0xaliplatin cell promote angiogenesis.}

Based on the proven important role of exosomes in intracellular conduction, we next examined the effects of exosomes derived from the $\mathrm{CM}$ of SW480/Oxaliplatin cell on promoting angiogenesis. After the exosomes were extracted, they were examined by TEM (Fig. 2A). Moreover, the expression of CD9, CD63, and CD81 (exosomal positive markers) were significantly increased (Fig. 2B). Then, the exosomes were labeled with PKH67 and co-cultured with HUVECs (Fig. 2C).

As shown in Fig. 3, the HUVECs co-cultured with the exosomes of SW480/Oxaliplatin cells had higher proliferation, migration, as well as tube formation than that of HUVECs co-cultured with the exosomes of SW480 cells (Fig. 3A, B and C). The SW480/Oxaliplatin cells exosomes also increased the mRAN levels and protein expression of VEGF and CD31 of HUVECs, compared with SW480 cells exosomes (Fig. 1D and E). Collectively, we found that SW480/Oxaliplatin exosomes promoted angiogenesis of HUVECs.

\subsection{BMP-2 increased in SW480/Oxaliplatin exosomes and enhanced angiogenesis via inhibiting the Smad signaling pathway.}

Next, we investigated the potential mechanisms by which SW480/0xaliplatin exosomes promoting angiogenesis. The results of Western Blotting showed that the expression of BMP-2 in SW480/Oxaliplatin exosomes was 2.3 folds higher than that in SW480 exosomes (Fig. 4A). BMP-2 is a member of transforming growth factor- $\beta$ / BMP superfamily, which exerts a variety of biological functions by regulating TGF- $\beta$ / Smad signaling pathways. Therefore, we then explored whether BMP-2 regulates Smad signaling pathway. BMPR2 was determined as a potential target of BMP-2 after co-culturing with HUVECs (Fig. 4B). The expression of BMPR2 was significantly increased in HUVECs co-cultured with SW480/Oxaliplatin exosomes compared to with SW480 exosomes (Fig. 3B). Studies have confirmed that Smad affects the POSTN transcription, which then enhancing angiogenesis. AS displayed in the Fig. 4C, compared with SW480 exosomes, SW480/Oxaliplatin exosomes decreased the phosphorylation Smad5 


\subsection{TGFB1 attenuated the enhanced angiogenesis caused by SW480/Oxaliplatin exosomes in HUVECs.}

Then TGF $\beta 1$, an activator of the TGF- $\beta /$ Smad signaling pathway, was used to verify our results above. After co-culture with SW480/Oxaliplatin exosomes, HUVECs were stimulated by $1 \mathrm{ng} / \mathrm{mL}$ TGF $\beta 1$. TGF $\beta 1$ obviously blocked the proliferation of HUVECs of SW480/Oxaliplatin exosomes (Fig. 5A). In addition, TGF $\beta 1$ weakened the effect of SW480/Oxaliplatin exosomes on cell migration and tube formation (Fig. 5B and C). Moreover, the inhibitory effect of SW480/Oxaliplatin exosomes on the Smad signaling pathway was also reversed by TGF $\beta 1$ (Fig. 5D).

\section{Discussion}

Multidrug resistance refers to the simultaneous resistance of tumor cells to various drugs with different structures and chemotherapy mechanisms [4]. Mechanisms of drug resistance have been reported including (1) activation of the drug target enzyme DNA topoisomerase $\mathrm{N}$ or detoxifying enzyme glutathione S-transferase [17]; (2) DNA self-repair [18]; (3) apoptosis resistance of cancer cells and changes in some signaling pathways [19]. ATP binding cassette (ABC) is one of the main causes of multidrug resistance of tumor cells, which can extract drugs from tumor cells to the outside of the cell through ATP-dependent membrane transporter to reduce the concentration of drugs in the cell [20]. However, how drug-resistant cancer cells regulate angiogenesis remains unclear. In this study, we found that exosomes derived from SW480/Oxaliplatin cells promoted cell proliferation and migration, and ultimately angiogenesis. The high levels of BMP-2 contained in SW480/Oxaliplatin exosomes promote angiogenesis by inhibiting the Smad signaling pathway.

Previous studies considered exosomes to be merely "fragments" of exogenous cells. An increasing number of studies have found that exosomes play an increasingly important role in mediating cell-to-cell communication [21, 22]. It can be taken up by the recipient cells by carrying a variety of molecules including proteins, miRNA, DNA and lipids, and play a series of biological roles in the recipient cells [22]. Tumor cell-derived or tumor-associated exosomes are closely related to the formation of tumor drug resistance [23]. Adriamycin resistant breast cancer cell line MCF-7 / ADR can mediate the formation of drug resistance of sensitive cells MCF-7 through exosomes [24]. Cancer associated fibroblasts (CAFs) secreted exosomes promote metastasis and chemotherapy resistance of CRC [25]. The main mechanisms of exosomes mediating the formation of tumor drug resistance are as follows [26, 27]:(1) exosomes carrying drugs out of the body; (2) exosomes delivering drug-resistant proteins, which are one of the main mechanisms mediating the formation of tumor drug resistance. (3) exosomes deliver non- 
coding RNAs (ncRNAs). In this study, we found that the proliferation, migration and catheterization of HUVECs co-cultured with SW480/Oxaliplatin exosomes were enhanced, suggesting that exosomes of drug-resistant cells could increase the angiogenesis of endothelial cells. It will be of great theoretical and practical significance to identify specific biomolecules that affect vascular production in exosomes of drug-resistant cells.

BMP2 mRNA expression has been found in breast cancer, and it has been shown that BMP2 promoted the proliferation of MCF-7 cells [28]. Hardwick et al. detected the expression of BMP-2 in colon tissue of 6 types of colon cancer and genetic adenomatous polyposis (FAP) patients and concluded that BMP-2 resulted in decreased apoptosis and cell adhesion in mature colon epithelial cells [29]. Sporadic earlyonset colorectal cancer (EOCRC) has increased expression of BMP2, which is different from APC mutated organs [30]. Smad4-deficient CRC cells induces high levels of BMP2 in fibroblasts, which enhances CRC invasiveness and metastasis [31]. Our study demonstrated that secretory BMP-2 acts as a tumor promoter by promoting angiogenesis in the tumor microenvironment. In addition, TGF- $\beta$ inhibited BMP2 mRNA expression in primary embryonic rats or osteocyte cultures [32]. Consistent with this, we found TGF 31 attenuated the enhanced angiogenesis caused by SW480/Oxaliplatin exosomes in HUVECs.

Smad5 is a TGF- $\beta$ superfamily protein that transmits signals from the cell membrane to the cell nucleus via the TGF- $\beta$ signaling pathway [33]. When Smad5 is degraded or deleted, normal signaling is disrupted, allowing cells to escape TGF- $\beta$-regulated growth inhibition and become cancerous [33]. The downregulation of Smad5 inhibited the expression of N-cadherin, matrix metallopeptidase 9, Snail, and Vimentin while elevating E-cadherin expression, thus inhibiting EMT, cell proliferation, migration, and invasion in NPC [34]. Through the interaction between TGF/Smad pathway and Wnt pathway, the TGF/Smad pathway can jointly coordinate the occurrence of tumor epithelial to mesenchymal transition (EMT) [35]. After the occurrence of tumor EMT, the expression of $\mathrm{N}$-mucin is increased. It weakens the adhesion between tumor cells, facilitates metastasis and infiltration, and promotes the movement and metastasis of tumor cells [36]. BMP-2 plays a different role in different stages of tumor progression by acting on the Smad signaling pathway. BMP-2 promotes epithelial-to-mesenchymal transition and breast cancer stemness via Rb and CD44-Smad4 signaling pathways [37]. The proliferation of ovarian cancer cell lines was enhanced by BMP2 and suppressed by Dorsomorphin via Smad5 in vitro [38]. BMP/Smad5 signaling plays an important role and, therefore, becomes a potential therapeutic target in serous ovarian cancer.

\section{Conclusion}

In summary, our results suggested that BMP-2-rich exosomes inhibited the Smad signaling pathway, thereby promoting angiogenesis and cell drug resistance. Our findings would provide new insights into the potential of BMP-2 as a novel anti-angiogenesis target in CRC.

\section{Declarations}


Availability of data and materials

For data availability, please contact the corresponding author.

\section{Funding}

This work was supported by the Natural Science Foundation of Anhui Province (2016QK056),Natural Science Foundation of Anhui Traditional Chinese Medicine区2020ccyb25区,Key Project of Education Department of Anhui Medical University (2019xkj218),Key Project of Education Department of Luan Hospital of Anhui province区2020kykt01区

\section{Competing interests}

The authors declare that they have no competing interests.

\section{Consent for publication}

Not applicable.

\section{Consent to participate}

Not applicable.

\section{Ethics approval}

Not applicable.

\section{Code availability}

Not applicable.

\section{Authors' contributions}

(I) Conception and design: Song Yang and Lei Yao ; (II) Administrative support: Xiaolong Wang; (III) Provision of study materials or patients: Hao Sun; (IV) Collection and assembly of data: Chaogang Du and Chengpeng Song ; (V) Data analysis and interpretation: Jingyu Fu; (VI) Manuscript writing: All authors; (VII) Final approval of manuscript: All authors.

\section{References}

1. Brody H. Colorectal cancer. Nature. 2015 May 14;521(7551):S1. doi: 10.1038/521S1a. PMID: 25970450.

2. Dienstmann R, Salazar R, Tabernero J. Personalizing colon cancer adjuvant therapy: selecting optimal treatments for individual patients. J Clin Oncol. 2015 Jun 1;33(16):1787-96. doi: 10.1200/JC0.2014.60.0213. Epub 2015 Apr 27. PMID: 25918287. 
3. Rivera Vargas T, Apetoh L. Danger signals: Chemotherapy enhancers? Immunol Rev. 2017 Nov;280(1):175-193. doi: 10.1111/imr.12581. PMID: 29027217.

4. Bukowski K, Kciuk M, Kontek R. Mechanisms of Multidrug Resistance in Cancer Chemotherapy. Int J Mol Sci. 2020 May 2;21(9):3233. doi: 10.3390/ijms21093233. PMID: 32370233; PMCID: PMC7247559.

5. Zhang H, Deng T, Liu R, Bai M, Zhou L, Wang X, Li S, Wang X, Yang H, Li J, Ning T, Huang D, Li H, Zhang L, Ying G, Ba Y. Exosome-delivered EGFR regulates liver microenvironment to promote gastric cancer liver metastasis. Nat Commun. 2017 Apr 10;8:15016. doi: 10.1038/ncomms15016. PMID: 28393839; PMCID: PMC5394240.

6. Pegtel DM, Gould SJ. Exosomes. Annu Rev Biochem. 2019 Jun 20;88:487-514. doi: 10.1146/annurev-biochem-013118-111902. PMID: 31220978.

7. Han K, Wang FW, Cao CH, Ling H, Chen JW, Chen RX, Feng ZH, Luo J, Jin XH, Duan JL, Li SM, Ma NF, Yun JP, Guan XY, Pan ZZ, Lan P, Xu RH, Xie D. CircLONP2 enhances colorectal carcinoma invasion and metastasis through modulating the maturation and exosomal dissemination of microRNA-17. Mol Cancer. 2020 Mar 18;19(1):60. doi: 10.1186/s12943-020-01184-8. Erratum in: Mol Cancer. 2021 Mar 31;20(1):60. PMID: 32188489; PMCID: PMC7079398.

8. Lu J, Wang YH, Yoon C, Huang XY, Xu Y, Xie JW, Wang JB, Lin JX, Chen QY, Cao LL, Zheng CH, Li P, Huang CM. Circular RNA circ-RanGAP1 regulates VEGFA expression by targeting miR-877-3p to facilitate gastric cancer invasion and metastasis. Cancer Lett. 2020 Feb 28;471:38-48. doi: 10.1016/j.canlet.2019.11.038. Epub 2019 Dec 5. PMID: 31811909.

9. Yu DD, Wu Y, Shen HY, Lv MM, Chen WX, Zhang XH, Zhong SL, Tang JH, Zhao JH. Exosomes in development, metastasis and drug resistance of breast cancer. Cancer Sci. 2015 Aug;106(8):959-64. doi:10.1111/cas.12715. Epub 2015 Jul 20. PMID: 26052865; PMCID: PMC4556383.

10. Yu DD, Wu Y, Shen HY, Lv MM, Chen WX, Zhang XH, Zhong SL, Tang JH, Zhao JH. Exosomes in development, metastasis and drug resistance of breast cancer. Cancer Sci. 2015 Aug;106(8):959-64. doi:10.1111/cas.12715. Epub 2015 Jul 20. PMID: 26052865; PMCID: PMC4556383.

11. Hu JL, Wang W, Lan XL, Zeng ZC, Liang YS, Yan YR, Song FY, Wang FF, Zhu XH, Liao WJ, Liao WT, Ding YQ, Liang L. CAFs secreted exosomes promote metastasis and chemotherapy resistance by enhancing cell stemness and epithelial-mesenchymal transition in colorectal cancer. Mol Cancer. 2019 May 7;18(1):91. doi: 10.1186/s12943-019-1019-x. PMID: 31064356; PMCID: PMC6503554.

12. Tian H, Zhao J, Brochmann EJ, Wang JC, Murray SS. Bone morphogenetic protein-2 and tumor growth: Diverse effects and possibilities for therapy. Cytokine Growth Factor Rev. 2017 Apr;34:7391. doi:10.1016/j.cytogfr.2017.01.002. Epub 2017 Jan 12. PMID: 28109670.

13. Yan HHN, Siu HC, Ho SL, Yue SSK, Gao Y, Tsui WY, Chan D, Chan AS, Wong JWH, Man AHY, Lee BCH, Chan ASY, Chan AKW, Hui HS, Cheung AKL, Law WL, Lo OSH, Yuen ST, Clevers H, Leung SY. Organoid cultures of early-onset colorectal cancers reveal distinct and rare genetic profiles. Gut. 2020 Dec;69(12):2165-2179. doi: 10.1136/gutjnl-2019-320019. Epub 2020 Mar 26. PMID: 32217638. 
14. Zhang J, Ge Y, Sun L, Cao J, Wu Q, Guo L, Wang Z. Effect of bone morphogenetic protein-2 on proliferation and apoptosis of gastric cancer cells. Int J Med Sci. 2012;9(2):184-92. doi:10.7150/ijms.3859. Epub 2012 Feb 15. PMID: 22359486; PMCID: PMC3283866.

15. Langenfeld EM, Kong Y, Langenfeld J. Bone morphogenetic protein-2-induced transformation involves the activation of mammalian target of rapamycin. Mol Cancer Res. 2005 Dec;3(12):67984. doi: 10.1158/1541-7786.MCR-05-0124. PMID: 16380505.

16. Feng PC, Ke XF, Kuang HL, Pan LL, Ye Q, Wu JB. BMP2 secretion from hepatocellular carcinoma cell HepG2 enhances angiogenesis and tumor growth in endothelial cells via activation of the MAPK/p38 signaling pathway. Stem Cell Res Ther. 2019 Aug 6;10(1):237. doi: 10.1186/s13287-019-1301-2. PMID: 31387619; PMCID: PMC6683571.

17. Szakács G, Paterson JK, Ludwig JA, Booth-Genthe C, Gottesman MM. Targeting multidrug resistance in cancer. Nat Rev Drug Discov. 2006 Mar;5(3):219 - 34. doi: 10.1038/nrd1984. PMID: 16518375.

18. Bukowski K, Kciuk M, Kontek R. Mechanisms of Multidrug Resistance in Cancer Chemotherapy. Int J Mol Sci. 2020 May 2;21(9):3233. doi: 10.3390/ijms21093233. PMID: 32370233; PMCID: PMC7247559.

19. Assaraf YG, Brozovic A, Gonçalves AC, Jurkovicova D, Linē A, Machuqueiro M, Saponara S, Sarmento-Ribeiro AB, Xavier CPR, Vasconcelos MH. The multi-factorial nature of clinical multidrug resistance in cancer. Drug Resist Updat. 2019 Sep;46:100645. doi:10.1016/j.drup.2019.100645. Epub 2019 Sep 17. PMID: 31585396.

20. Mohammad IS, He W, Yin L. Understanding of human ATP binding cassette superfamily and novel multidrug resistance modulators to overcome MDR. Biomed Pharmacother. 2018 Apr;100:335-348. doi: 10.1016/j.biopha.2018.02.038. Epub 2018 Feb 16. PMID: 29453043.

21. Kalluri R, LeBleu VS. The biology, function, and biomedical applications of exosomes. Science. 2020 Feb 7;367(6478):eaau6977. doi: 10.1126/science.aau6977. PMID: 32029601; PMCID: PMC7717626.

22. Batrakova EV, Kim MS. Using exosomes, naturally-equipped nanocarriers, for drug delivery. J Control Release. 2015 Dec;10:219:396-405. doi:10.1016/j.jconrel.2015.07.030. Epub 2015 Aug 1. PMID: 26241750; PMCID: PMC4656109.

23. Zhang L, Yu D. Exosomes in cancer development, metastasis, and immunity. Biochim Biophys Acta Rev Cancer. 2019 Apr;1871(2):455-68. doi:10.1016/j.bbcan.2019.04.004. Epub 2019 Apr 30. PMID: 31047959; PMCID: PMC6542596.

24. Wang X, Xu C, Hua Y, Sun L, Cheng K, Jia Z, Han Y, Dong J, Cui Y, Yang Z. Exosomes play an important role in the process of psoralen reverse multidrug resistance of breast cancer. $J$ Exp Clin Cancer Res. 2016 Dec 1;35(1):186. doi: 10.1186/s13046-016-0468-y. PMID: 27906043; PMCID: PMC5131502.

25. Hu JL, Wang W, Lan XL, Zeng ZC, Liang YS, Yan YR, Song FY, Wang FF, Zhu XH, Liao WJ, Liao WT, Ding YQ, Liang L. CAFs secreted exosomes promote metastasis and chemotherapy resistance by enhancing cell stemness and epithelial-mesenchymal transition in colorectal cancer. Mol Cancer. 2019 May 7;18(1):91. doi: 10.1186/s12943-019-1019-x. PMID: 31064356; PMCID: PMC6503554. 
26. Mashouri L, Yousefi H, Aref AR, Ahadi AM, Molaei F, Alahari SK. Exosomes: composition, biogenesis, and mechanisms in cancer metastasis and drug resistance. Mol Cancer. 2019 Apr 2;18(1):75. doi: 10.1186/s12943-019-0991-5. PMID: 30940145; PMCID: PMC6444571.

27. Milman N, Ginini L, Gil Z. Exosomes and their role in tumorigenesis and anticancer drug resistance. Drug Resist Updat. 2019 Jul;45:1-12. doi:10.1016/j.drup.2019.07.003. Epub 2019 Jul 23. PMID: 31369918.

28. Raida M, Clement JH, Leek RD, Ameri K, Bicknell R, Niederwieser D, Harris AL. Bone morphogenetic protein 2 (BMP-2) and induction of tumor angiogenesis. J Cancer Res Clin Oncol. 2005 Nov;131(11):741-50. doi:10.1007/s00432-005-0024-1. Epub 2005 Nov 1. PMID: 16136355.

29. Hardwick JC, Van Den Brink GR, Bleuming SA, Ballester I, Van Den Brande JM, Keller JJ, Offerhaus GJ, Van Deventer SJ, Peppelenbosch MP. Bone morphogenetic protein 2 is expressed by, and acts upon, mature epithelial cells in the colon. Gastroenterology. 2004 Jan;126(1):111 - 21. doi: 10.1053/j.gastro.2003.10.067. PMID: 14699493.

30. Yan HHN, Siu HC, Ho SL, Yue SSK, Gao Y, Tsui WY, Chan D, Chan AS, Wong JWH, Man AHY, Lee BCH, Chan ASY, Chan AKW, Hui HS, Cheung AKL, Law WL, Lo OSH, Yuen ST, Clevers H, Leung SY. Organoid cultures of early-onset colorectal cancers reveal distinct and rare genetic profiles. Gut. 2020 Dec;69(12):2165-2179. doi: 10.1136/gutjnl-2019-320019. Epub 2020 Mar 26. PMID: 32217638.

31. Panda PK, Naik PP, Praharaj PP, Meher BR, Gupta PK, Verma RS, Maiti TK, Shanmugam MK, Chinnathambi A, Alharbi SA, Sethi G, Agarwal R, Bhutia SK. Abrus agglutinin stimulates BMP-2dependent differentiation through autophagic degradation of $\beta$-catenin in colon cancer stem cells. Mol Carcinog. 2018 May;57(5):664-677. doi: 10.1002/mc.22791. Epub 2018 Mar 14. PMID: 29457276.

32. Katagiri T, Yamaguchi A, Komaki M, Abe E, Takahashi N, Ikeda T, Rosen V, Wozney JM, FujisawaSehara A, Suda T. Bone morphogenetic protein-2 converts the differentiation pathway of $\mathrm{C} 2 \mathrm{C} 12$ myoblasts into the osteoblast lineage. J Cell Biol. 1994 Dec;127(6 Pt 1):1755-66. doi: 10.1083/jcb.127.6.1755. Erratum in: J Cell Biol 1995 Feb;128(4):following 713. PMID: 7798324; PMCID: PMC2120318.

33. Orlowski J. SMAD5 signaling: more than meets the nuclei. Cell Res. 2017 Sep;27(9):1075-6. doi:10.1038/cr.2017.101. Epub 2017 Aug 15. PMID: 28809394; PMCID: PMC5587846.

34. Zheng YJ, Zhao JY, Liang TS, Wang P, Wang J, Yang DK, Liu ZS. Long noncoding RNA SMAD 5-AS1 acts as a microRNA-106a-5p sponge to promote epithelial mesenchymal transition in nasopharyngeal carcinoma. FASEB J. 2019 Nov;33(11):12915-28. doi:10.1096/fj.201900803R. Epub 2019 Sep 26. PMID: 31557058; PMCID: PMC6902713.

35. Zeng Y, Zhu J, Shen D, Qin H, Lei Z, Li W, Huang JA, Liu Z. Repression of Smad4 by miR205 moderates TGF- $\beta$-induced epithelial-mesenchymal transition in A549 cell lines. Int J Oncol. 2016 Aug;49(2):700-8. doi: 10.3892/ijo.2016.3547. Epub 2016 May 31. Erratum in: Int J Oncol. 2021 Feb;58(2):276-277. PMID: 27279345. 
36. Li HL, Li QY, Jin MJ, Lu CF, Mu ZY, Xu WY, Song J, Zhang Y, Zhang SY. A review: hippo signaling pathway promotes tumor invasion and metastasis by regulating target gene expression. J Cancer Res Clin Oncol. 2021 Jun;147(6):1569-85. doi: 10.1007/s00432-021-03604-8. Epub 2021 Apr 17. PMID: 33864521.

37. Huang P, Chen A, He W, Li Z, Zhang G, Liu Z, Liu G, Liu X, He S, Xiao G, Huang F, Stenvang J, Brünner $\mathrm{N}$, Hong A, Wang J. BMP-2 induces EMT and breast cancer stemness through Rb and CD44. Cell Death Discov. 2017 Jul 17;3:17039. doi: 10.1038/cddiscovery.2017.39. PMID: 28725489; PMCID: PMC5511860.

38. Peng J, Yoshioka Y, Mandai M, Matsumura N, Baba T, Yamaguchi K, Hamanishi J, Kharma B, Murakami R, Abiko K, Murphy SK, Konishi I. The BMP signaling pathway leads to enhanced proliferation in serous ovarian cancer-A potential therapeutic target. Mol Carcinog. 2016 Apr;55(4):335-45. doi: 10.1002/mc.22283. Epub 2015 Feb 7. PMID: 25663289.

\section{Tables}

Table 1

Primer sequences used for qRT-PCR

\begin{tabular}{|ll|}
\hline Genes & Primer Sequences $\left(\mathbf{5}^{\prime} \rightarrow \mathbf{3}^{\prime}\right)$ \\
\hline CD31 & F: AACAGTGTTGACATGAAGAGCC \\
& R: TGTAAAACAGCACGTCATCCTT \\
VEGF & F: GCACATAGAGAGAATGAGCTTCC \\
& R: CTCCGCTCTGAACAAGGCT \\
\hline B-actin & F: CGTAAAGACCTCTATGCCAACA \\
\hline & R: CGGACTCATCGTACTCCTGCT \\
\hline
\end{tabular}

\section{Figures}



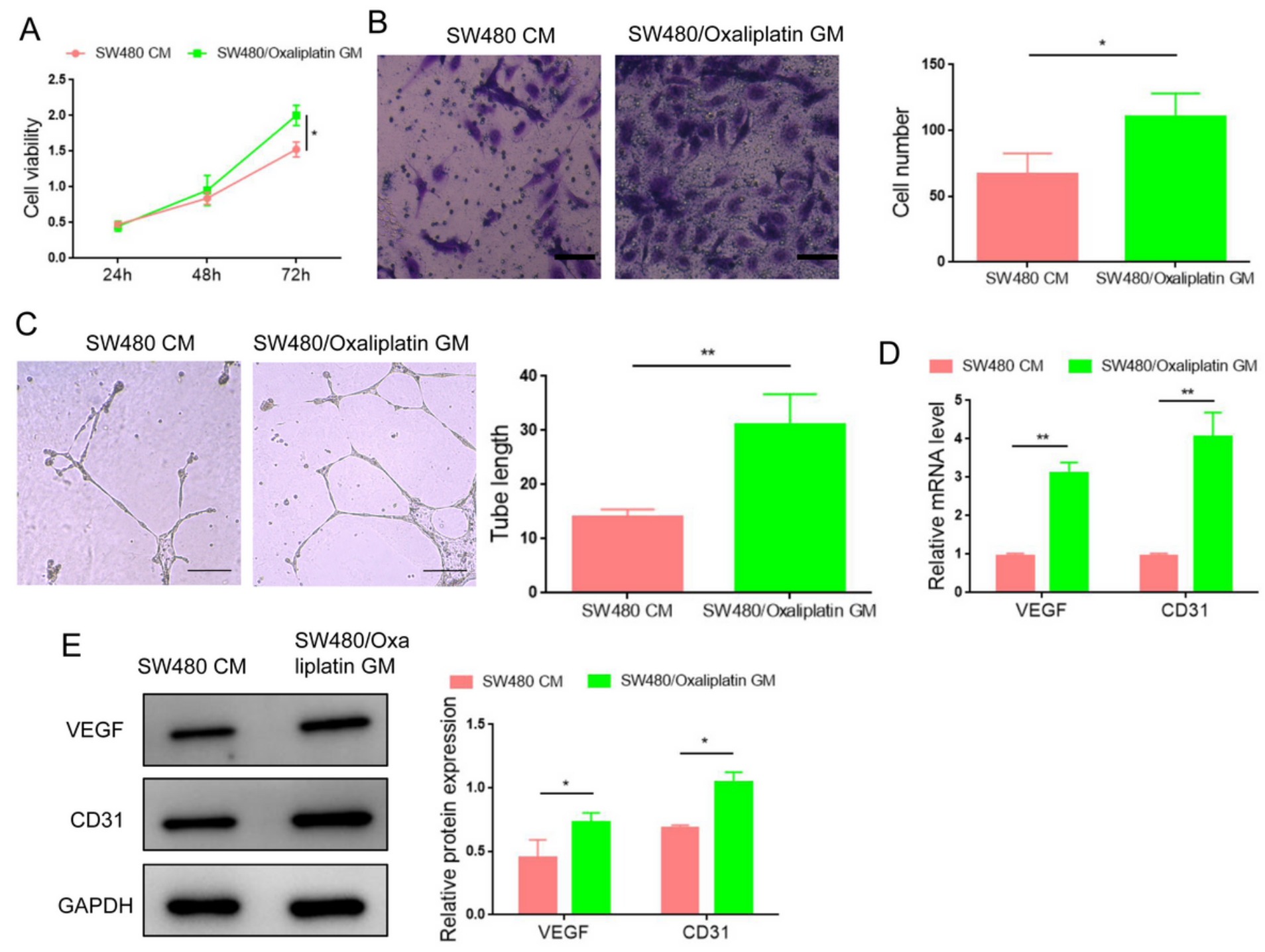

\section{Figure 1}

Conditioned medium (CM) extracted from SW480-resistant colon cancer cells enhance angiogenesis. HUVECs treated with CM of SW480/Oxaliplatin and SW480 cells. (A) Proliferation assay of HUVECs. (B) The Transwell assay determined the HUVECs migration. (C) Photomicrographs of tube-like structures and quantification of the tube number. (D) The mRNA level of VEGF and CD31. (E) Then protein expression of CD31 and VEGF in HUVECs. Data are shown as the means $\pm S D$. ${ }^{*} P<0.05, * * P<0.01$. 

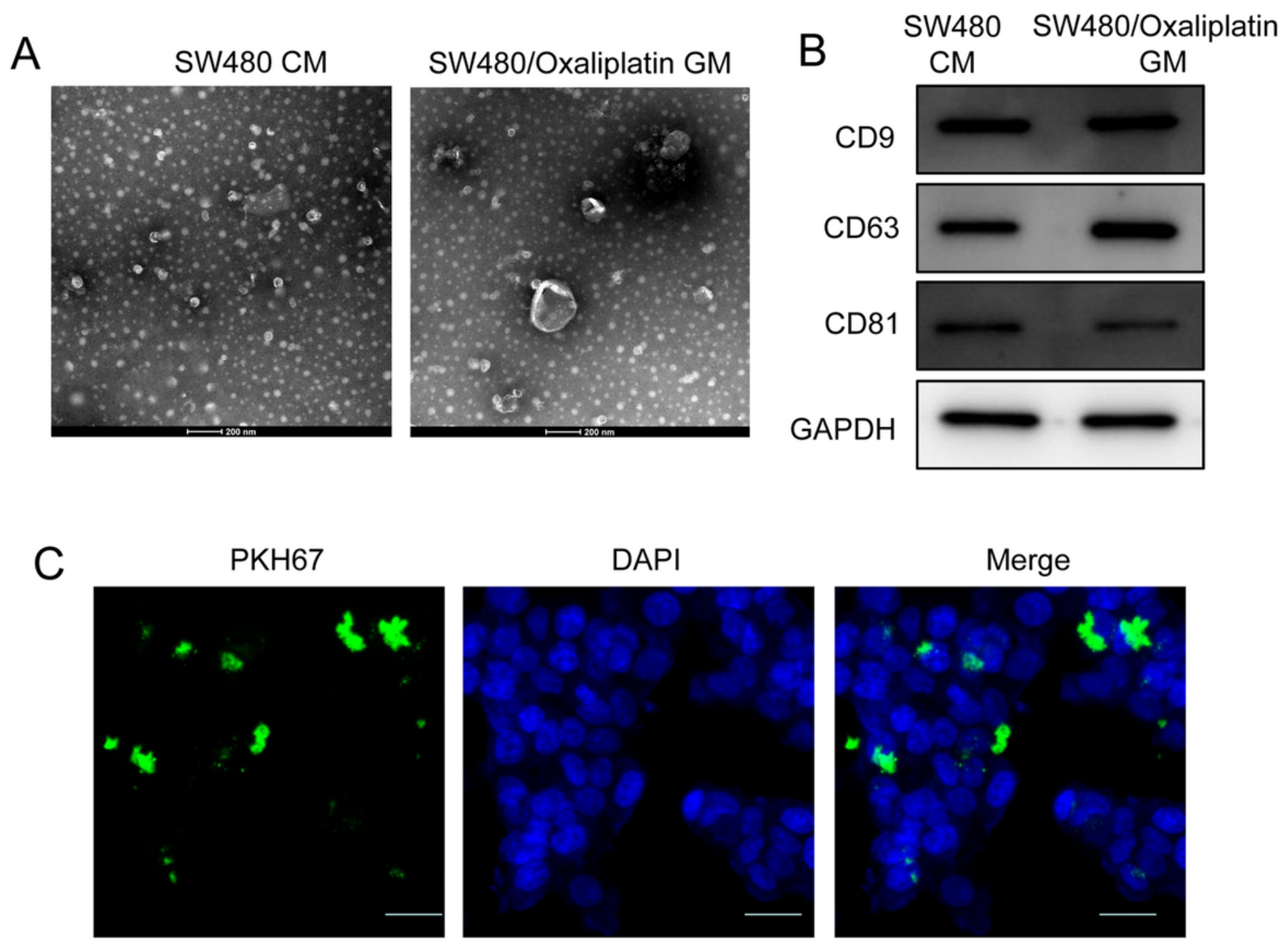

DAPI

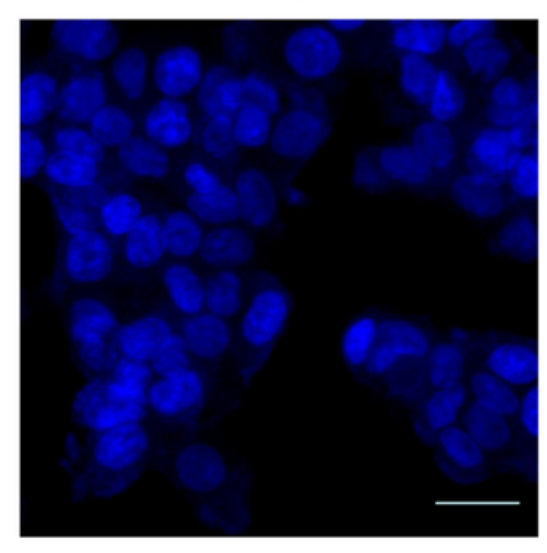

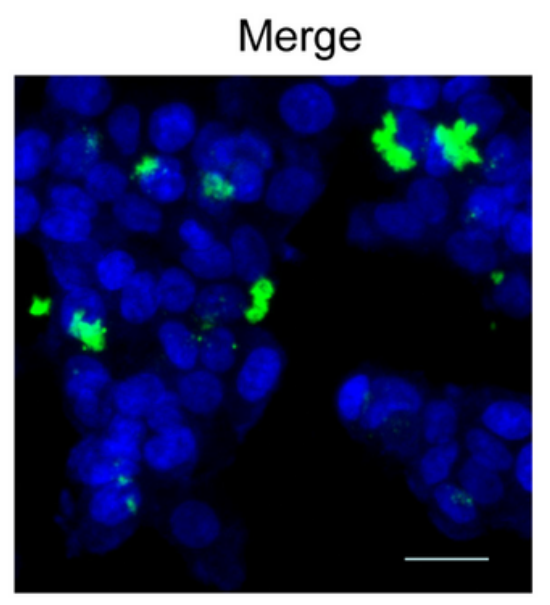

Figure 2

Characterization of exosomes of SW480/Oxaliplatin cells. (A)Transmission electron photomicrograph of exosomes. (B) Protein expression of CD9, CD63 and CD81. (C) Confocal images of PKH67-labeled exosomes taken up by HUVECs. Data are shown as the means $\pm S D$. ${ }^{*} P<0.05, * \star P<0.01$. 

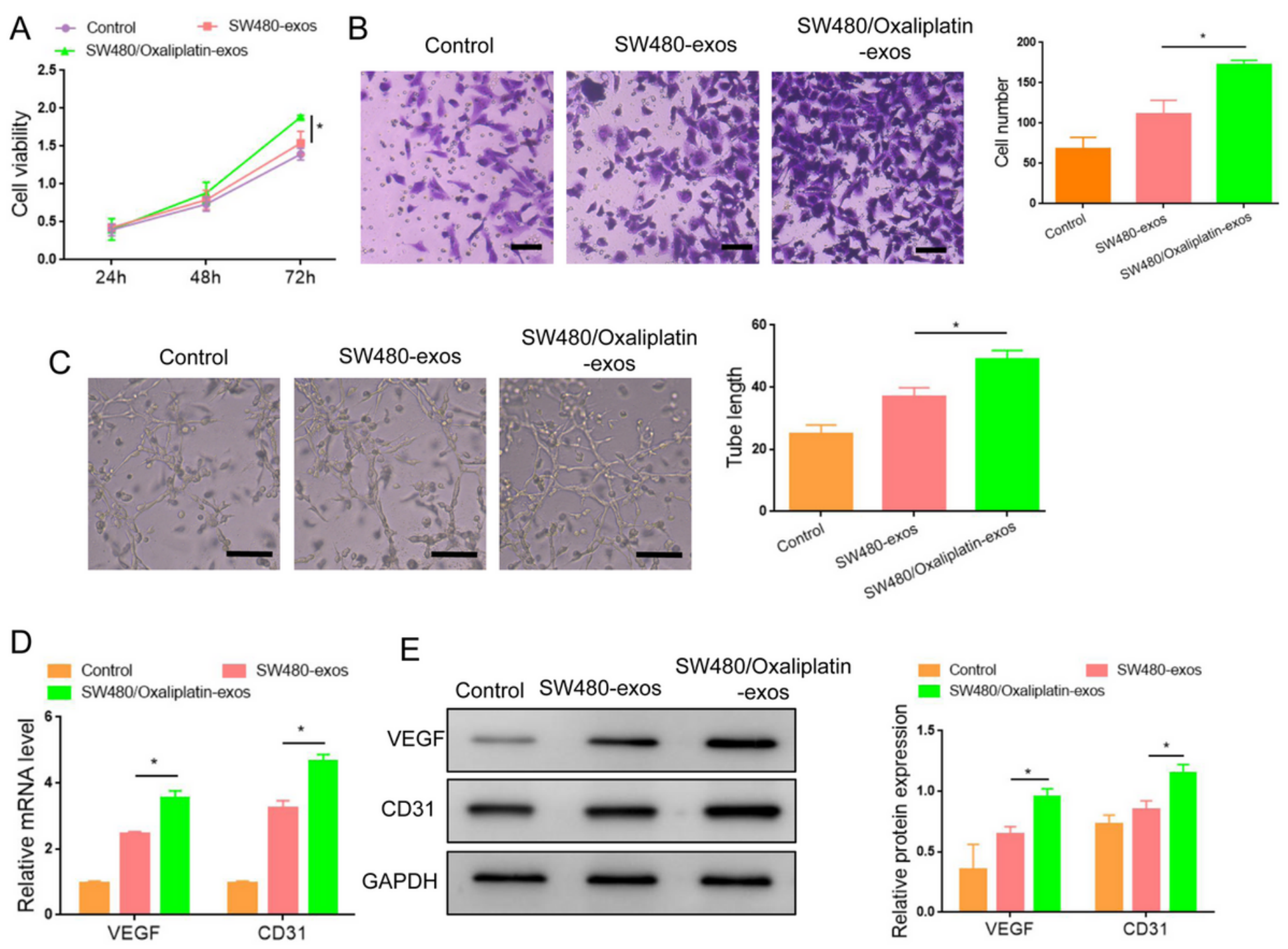

Figure 3

SW480/Oxaliplatin cell-derived exosomes accelerate angiogenesis. Exosomes were extracted from SW480/Oxaliplatin and SW480 cells and then co-cultured with HUVECs. (A) Proliferation assay of HUVECs. (B) The Transwell assay determined the HUVECs migration. (C) Photomicrographs of tube-like structures and quantification of the tube number. (D) The mRNA level of VEGF and CD31. (E) The protein expression of CD31 and VEGF in HUVECs. Data are shown as the means $\pm S D$. ${ }^{*} P<0.05,{ }^{\star} * P<0.01$. 
A

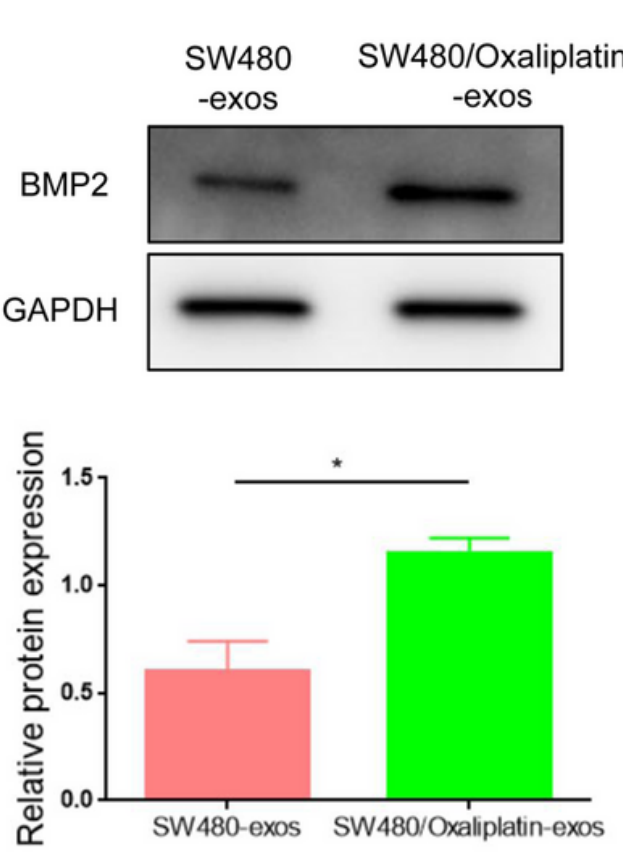

C

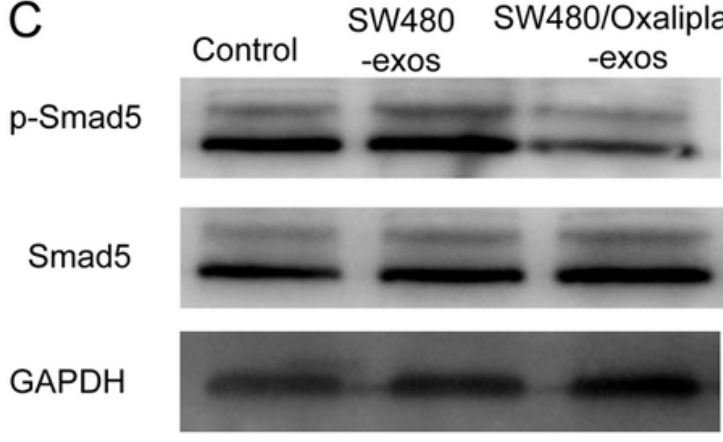

B
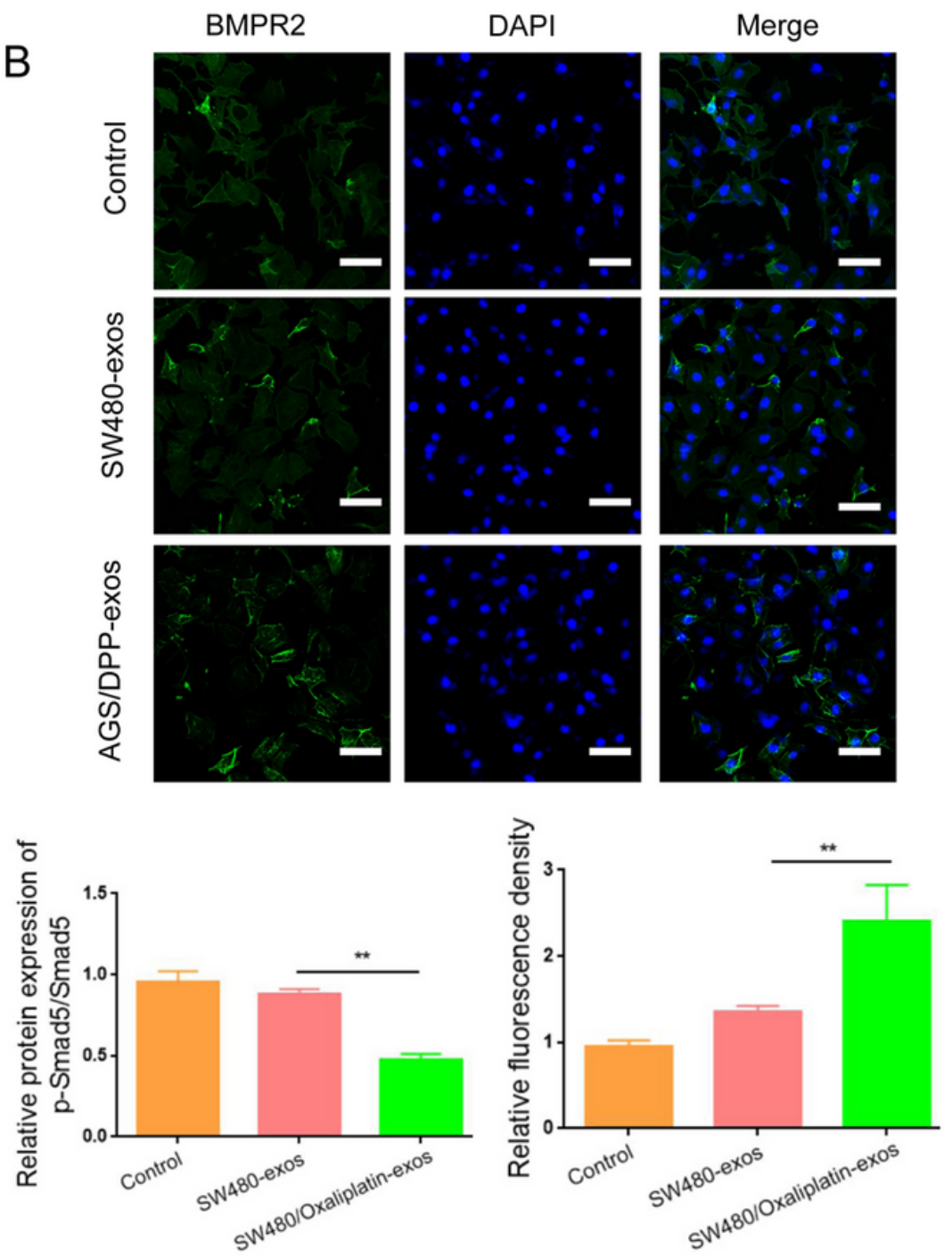

\section{Figure 4}

SW480/Oxaliplatin exosomes are enriched in BMP-2, which improve angiogenesis via the inhibition of the Smad signaling pathway. (A) The expression of BMP-2 in exosomes. (B) The expression of BMPR2 detected by Immunofluorescence. (C) The protein expression of p-Smad5 and Smad5 in HUVECs. Data are shown as the means \pm SD. ${ }^{*} P<0.05, * \star P<0.01$. 
A

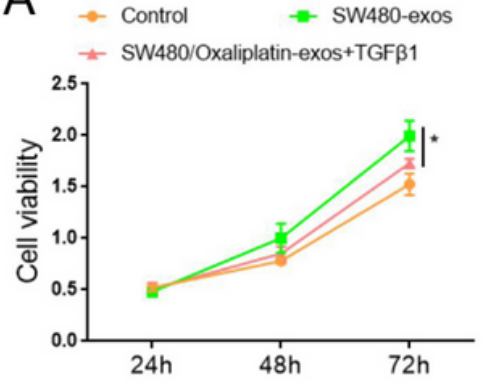

B

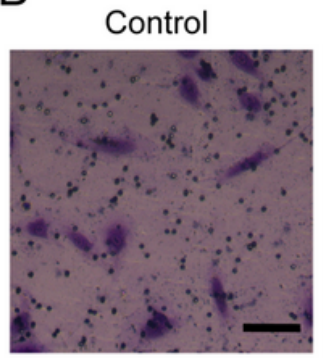

SW480

-exos

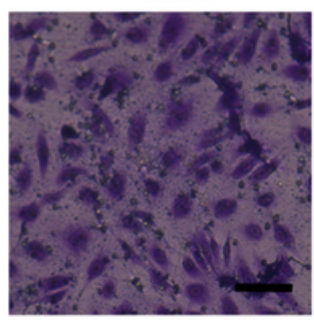

SW480/Oxaliplatin

C

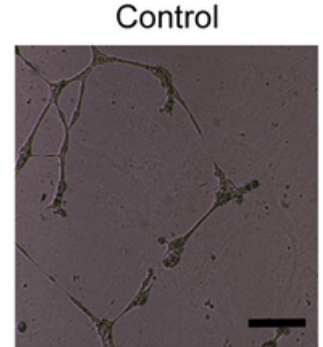

SW480

-exos

$>$ -exos+TGF $\beta 1$
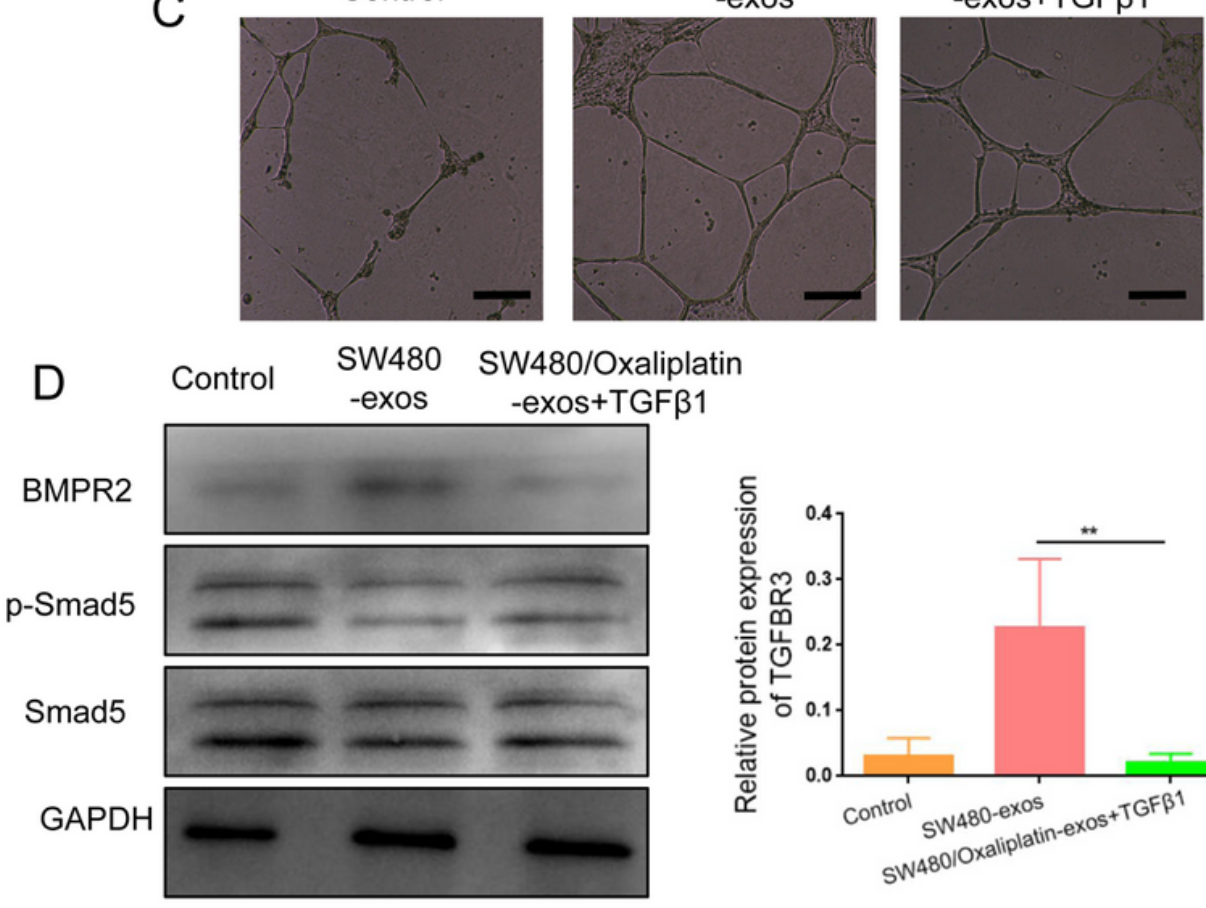

SW480/Oxaliplatin -exos+TGF $\beta 1$
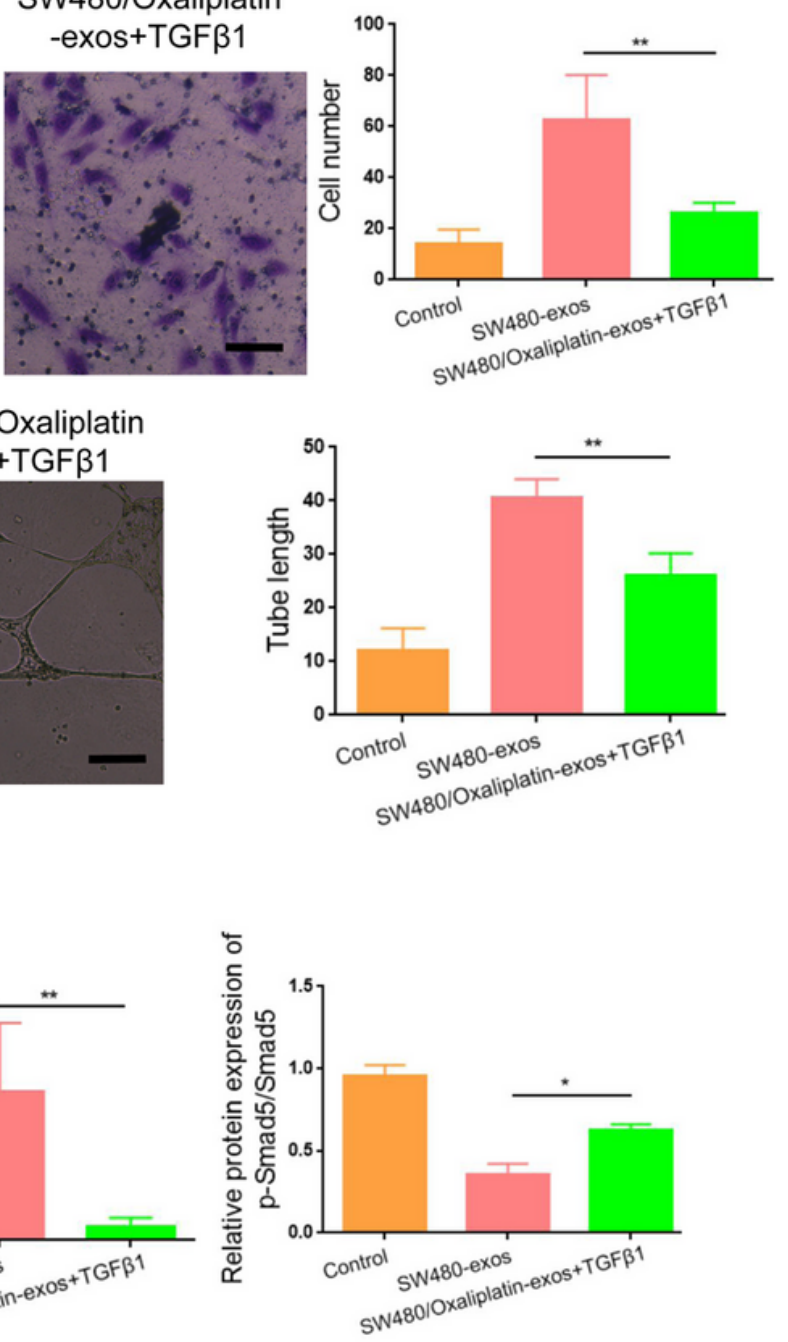

\section{Figure 5}

TGF $\beta 1$ neutralize the increased angiogenesis caused by SW480/Oxaliplatin exosomes. HUVECs were cocultured with SW480/Oxaliplatin exosomes $(40 \mu \mathrm{g} / \mathrm{mL})$ with or without the treatment of TGF $\beta 1$ (1 $\mathrm{ng} / \mathrm{mL}$ ). (A) Proliferation assay of HUVECs. (B) The Transwell assay determined the HUVECs migration. (C) Photomicrographs of tube-like structures and quantification of the tube number. (D) The protein expression of BMPR2, p-Smad5 and Smad5 in HUVECs. Data are shown as the means \pm SD. ${ }^{*}<<0.05$, ** $\mathrm{P}<0.01$. 